\title{
MOTIVOS DE CONSUMO DE PROGRAMAS TAURINOS EN TELEVISIÓN
}

\section{REASONS OF BULLFIGHTING PROGRAMMES CONSUMPTION IN TELEVISION}

Javier Pérez-González. Universidad de Zaragoza. España.

Carmen Marta-Lazo' ${ }^{1}$ Universidad de Zaragoza. España.

cmarta@unizar.es

\section{RESUMEN}

Este artículo de investigación pretende analizar los principales argumentos por los que un sector de la audiencia televisiva en España se interesa por el visionado de la programación de contenido taurino. También intenta examinar las motivaciones de aquellos televidentes que no siguen esta temática, así como profundizar en los argumentos de su rechazo o falta de interés. Con objeto de examinar estas razones, hemos utilizado como técnica de análisis cualitativo los grupos de discusión. De esta forma, conoceremos los motivos por los cuales un segmento de público selecciona para su consumo este tipo de contenidos. Además, la técnica cualitativa de los grupos de discusión nos permitirá profundizar en unos cuantos casos específicos y particulares para llegar a conocer el porqué de estas acciones. Por tanto, mediante el análisis del discurso de varios casos investigaremos los motivos principales por los que una parte de la sociedad española decide ver o no este tipo de programas.

PALABRAS CLAVE: televisión, programación taurina, consumo, grupos de discusión, audiencias, recepción, cultura.

\section{ABSTRACT}

This research article pretends to analyse the main arguments why a sector of television audiencein Spain is interested in bullfighting programming content. It also pretends to examine the motivations of those viewers who do not follow this subject, as well as fathom the arguments for rejection or lack of interest.In order to examine these reasons, we have used a qualitative analysis: focus groups. This way, we will know the reasons why a segment of the public selects this type of content. In addition, this qualitative technique will allow us to deepen into a few specific and particular cases to get to know the reason for these actions. Therefore, by analysing the speech of several cases, we will investigate the main reasons whya part of the Spanish society decides to watch or not such programs.

KEY WORDS: televisión, bullfighting programmes, consumption, focus groups, audience, reception, culture.

\footnotetext{
${ }^{1}$ Carmen Marta Lazo: Universidad de Zaragoza. Departamento de Lingüística General e Hispánica.
} 


\section{Cómo citar el artículo:}

Pérez-González J. y Marta-Lazo, C. (2014). Motivos de consumo de programas taurinos en televisión. Revista de Ciencias de la Comunicación e Información, 19, 55-72.

http://doi.org/10.35742/revistacccomunicacioneinformacion.2014.19.55-72

\section{INTRODUCCIÓN}

El análisis del presente trabajo se centra en los motivos que llevan a parte de la audiencia a consumir programación taurina en televisión. Al ser una materia abierta a diversas apreciaciones, es necesario estudiar el anclaje jurídico de la misma.

El poder legislativo reside en un Parlamento elegido democráticamente por sufragio universal. Partiendo de esta premisa, podemos afirmar que las leyes que emanan del legislador son un fiel reflejo de la voluntad mayoritaria. En todo Estado de Derecho, la presencia de lagunas jurídicas es habitual, especialmente en materias que pueden herir sensibilidades. Sin embargo, la legislación define de manera precisa y clara lo que significa la Tauromaquia para el Estado español y los deberes que este debe guardar. Así, la Ley sobre potestades administrativas en materia de espectáculos taurinos, aprobada en el año 1991, afirma lo siguiente: "La Administración podrá adoptar medidas destinadas a fomentar y proteger las actividades a las que se refiere la presente Ley, en atención a la tradición y vigencia cultural de la Fiesta de los Toros".

De hecho, la ley no solo apunta al deber de protección y atención del Estado español con respecto a la Fiesta de los Toros, sino que recientemente se ha ampliado esta legislación para hacer de los toros una materia íntegramente ligada al sector cultural. De esta manera, el Real Decreto 1151/2011 de 29 de julio establece lo siguiente: "Entendida la Tauromaquia como una disciplina artística y un producto cultural, las competencias del Estado en orden a su fomento y protección tienen su correcta ubicación en el Ministerio de Cultura".

Por lo tanto, atendiendo a lo dictado por el legislador y obedeciendo a la objetividad legislativa, aunque entendiendo que lo taurino siempre está sujeto a la opinión personal del individuo, en esta investigación se abordará la programación taurina desde la vertiente de la programación cultural.

Si consideramos lo taurino como un producto cultural, se ha de considerar la programación taurina como "servicio público esencial", término que aparece en el Preámbulo de la Ley General de la Comunicación Audiovisual, para la parte de población española seguidora de este tipo de contenidos. Si bien ofertar esta programación en la televisión privada obedece a la posible rentabilidad económica, son de obligada emisión en la televisión pública:

El Estatuto de RTVE, Ley 1/1980, define los principios que deben regir la programación de la televisión pública (...) Estos principios son: (...) el respeto al pluralismo político, religioso, social, cultural y lingüístico. Todos ellos 
garantizan la existencia de programas para todos los gustos e intereses; alcanza a todas las edades, clases sociales y grupos con formación educativa y cultural diferente (Medina Laverón, 2006, p. 18).

Además, el carácter de servicio público debe defender la emisión de este tipo de contenidos ante un eventual fracaso en términos de audiencia:

El servicio público lleva a proteger una serie de informaciones que no son rentables desde el punto de vista de la audiencia pero que no deben desaparecer de la agenda informativa. (...) Ese servicio a las minorías llevaría a plantear el servicio público como aportación de valores a la sociedad. Valores de sensibilidad, de cultura, de acceso al conocimiento o de entretenimiento de calidad. Una televisión que aporte valores a la sociedad y que no necesariamente gane dinero (García Matilla, 2010, p. 77).

Sin embargo, aunque la programación taurina no ha perdido su condición de producto cultural y, por tanto, sigue siendo considerada un producto de servicio público, se han desarrollado en los últimos años una serie de leyes que ponen en duda la idoneidad de este tipo de emisiones en algunas franjas horarias.

De hecho, la Ley 17/2006 de la radio y la televisión de titularidad estatal, antecedente de la Ley 7/2010 de Comunicación General Audiovisual, sirvió como inspiración para que RTVE elaborara un Manual de Estilo en ese mismo año. En dicho Manual, dentro del apartado Violencia con Animales, se recoge lo siguiente: "RTVE no emitirá corridas de toros por su horario, generalmente coincidente con el horario protegido o de especial protección para la infancia". Sin embargo, dicho precepto fue eliminado el pasado año 2011, lo que permitió que TVE volviera a emitir corridas de toros.

Esta medida no estuvo exenta de polémica. Mientras que parte de la sociedad celebraba la vuelta de los toros a la televisión pública -hay que recordar que en este tiempo la Tauromaquia no ha dejado de ser considerada, desde el punto de vista del legislador, como un producto cultural-, otros defendían que mediante la emisión de esos contenidos se estaban vulnerando los derechos del menor recogidos en la Ley General de Comunicación Audiovisual del 2010.

En cualquier caso, desde que desapareció del Manual de Estilo la referencia expresa a la prohibición de emitir corridas de toros, TVE puede emitir, sin repercusión legal alguna, las corridas de toros que estime oportunas siempre y cuando se cumplan otra serie de parámetros, como puede ser el coste de la emisión. Dejando de lado la perspectiva jurídica de la cuestión, es innegable el arraigo que la Tauromaquia ha tenido, desde un punto de vista socio-cultural, en nuestro país durante muchos siglos. Además, esta tradición también se tradujo en innumerables emisiones televisivas durante la segunda mitad del siglo pasado. Sin embargo, pocos son los estudios que han indagado en la relación existente entre la audiencia de espectáculos taurinos y la televisión. De hecho, apenas existen análisis de las motivaciones que llevan a parte de la población a visionar este tipo de programación, hasta el punto de que estos son casi inexistentes (De Haro de San Mateo, 2011, p. 52). 
Un análisis sobre las causas que llevan a parte de la población española a consumir este producto audiovisual es algo que puede resultar interesante y novedoso dentro del panorama de investigaciones sobre la relación entre la Tauromaquia y los medios de comunicación.

Es precisamente la novedad que aporta un tema un buen parámetro a la hora de medir el impacto potencial de una investigación (Marta-Lazo, 2009, pp. 49-51). Pero no solo se ha de atender al carácter novedoso del trabajo, también se puede determinar la importancia de un proyecto desde un punto de vista social, es decir, desde su finalidad como servicio público. Por ello, consideramos que relacionar las retransmisiones televisivas y las corridas de toros es una de las principales aportaciones del presente trabajo. Además, enfatizamos el interés en conocer las motivaciones y las causas del consumo de este tipo de contenidos por parte de la sociedad.

Aunque las emisiones taurinas no despierten tanto seguimiento como en épocas pretéritas, no deja de ser cierto que la audiencia de este tipo de programas es fiel y numerosa cuando se dan las condiciones para ello. Para sustentar esta afirmación basta con acudir al share del único programa de televisión taurino en la actualidad, Tendido Cero. Este veterano espacio apenas alcanza de media el $3 \%$ en sus emisiones habituales. Sin embargo, resulta sorprendente comprobar cómo incrementa la audiencia cuando las emisiones taurinas se realizan en un horario más favorable, como sucedió el pasado mes de septiembre de 2013 cuando TVE emitió una corrida de toros a las 17:00 h. Ese día, la cadena pública estatal volvió a emitir una corrida de toros seis años después del cese de las emisiones. Los datos de audiencia de esta corrida coinciden plenamente con las cifras arrojadas en el último festejo ofrecido, correspondiente a la Feria del Pilar del 2006.

Según un informe de Barlovento Comunicación con datos ofrecidos por Kantar Media, 1.157.000 personas vieron la corrida. Este dato se traduce en un 12,7\% de cuota de pantalla. Estas cifras estuvieron por encima de la cuota de pantalla de la cadena en ese mes de septiembre. Además, la tarde del miércoles, fecha de celebración del festejo, superó ampliamente los datos de las dos tardes previas, que apenas superaban el $8 \%$. El informe de Kantar Media también refleja el seguimiento por Comunidades Autónomas. En varias de ellas, los toros tuvieron en torno a un $20 \%$ de cuota de pantalla destacando por encima del resto Castilla-León con un $31,9 \%$ y Murcia con un $24 \%$. Además, Castilla-La Mancha, Aragón y País Vasco también estuvieron por encima de la media nacional.

Es significativa la polémica que hubo en torno a la emisión de esta corrida. Como es lógico, la sociedad española no es enteramente taurina, por lo que la vuelta de los toros a la televisión pública se encontró con la negativa de parte de la sociedad. De hecho, algunos colectivos llegaron a acusar a RTVE de incumplir varios de los preceptos del ya mencionado Manual de Estilo.

En todo caso, tanto los datos que arroja Tendido Cero como los ofrecidos por Kantar Media tras la corrida del pasado mes de septiembre muestran el interés de parte de la sociedad por la Tauromaquia. Interés que, como hemos comentado en la primera parte del presente análisis, se encuentra legitimado tanto por los códigos normativos de nuestro país como por la propia Constitución. 
Además de TVE, solamente Canal + ha apostado por los toros en los últimos tiempos. A comienzos de siglo, el canal propiedad de Sogecable emitía las corridas más destacadas del año a través de Canal +1 , cuyo acceso estaba permitido a todos los clientes. Sin embargo, Sogecable creó en 2011 un canal específico para los aficionados a los toros: Canal + toros.

Otro de los principales motivos de la realización de esta investigación se encuentra en la enorme influencia que los toros han ejercido a lo largo de la historia sobre la cultura española y latinoamericana. No solo, como hemos comentado, los toros han sido compañeros de viaje de la prensa escrita, la radio o la televisión en nuestro país desde su nacimiento, sino que también han ejercido su influencia sobre otras áreas culturales como la música, la moda, el cine o la literatura (Rivera Flores, 2010, p. 125).

\section{OBJETIVOS}

Los objetivos generales en los que se centra nuestro estudio se relacionan con las líneas de actuación basadas en:

- Analizar los motivos que llevan a un sector de la audiencia a visionar contenidos taurinos.

- Analizar los motivos que llevan a gran parte de la población a no visionar contenidos taurinos.

- Comparar las motivaciones de ambos colectivos.

- Determinar el grado de fidelidad de la audiencia de programas taurinos.

- Explicar cómo se perciben los mensajes audiovisuales procedentes de los programas televisivos taurinos en función del sexo y la edad.

- Comparar las diferencias, si las hay, entre quienes ven estos programas de forma solitaria y los que realizan el visionado acompañados.

- Comprobar si la escasa oferta televisiva de espectáculos taurinos en el ente público es causa de su escasa audiencia.

\section{METODOLOGÍA}

Las técnicas cualitativas son de notable utilidad cuando se quieren conocer los motivos por los cuales determinados grupos de personas optan por consumir unos programas de televisión determinados. Por esta razón, mediante el presente análisis estudiaremos los motivos de consumo de programas taurinos en televisión mediante una técnica cualitativa: los grupos de discusión.

La investigación cualitativa nos permitirá estudiar los temas con detalle, ya que podremos profundizar en unos pocos casos. Además, esta técnica permite una recolección de datos más informal y relajada, algo que es beneficioso tanto para el sujeto encargado de obtener la información como para los propios participantes en el grupo. Otra de las ventajas de la investigación cualitativa es que el investigador no se verá encorsetado en una serie de cuestiones específicas y cerradas, sino que podrá manejar la interacción en el grupo como si de una conversación se tratara.

Con el grupo focal se tratará de: identificar la naturaleza de las realidades, determinar la fuerza de asociación o correlación entre variables, identificar el sistema 
de relaciones y su estructura dinámica. De esta manera, la investigación nos permitirá conocer por qué las cosas suceden o por qué no suceden.

Como venimos comentando, creemos que la mejor manera de estudiar el comportamiento de la audiencia son los grupos de discusión. Además de las ventajas enumeradas anteriormente, se destacan las siguientes:

El grupo de discusión ayuda a comprender los motivos del comportamiento y actitudes de la audiencia o los consumidores. La característica definitoria del grupo de discusión es la creación de una discusión en grupo controlada, que se utiliza para obtener información preliminar sobre un determinado proyecto de investigación, comprender las razones subyacentes de un fenómeno en particular o someter a prueba las ideas o hipótesis de partida (Wimmer y Dominick, 1996, p. 154).

Para nuestro estudio constituimos dos grupos de discusión de 7 personas cada uno. Decidimos escoger solo 7 sujetos para conformar cada grupo porque un número mayor de personas podría haber dificultado la participación de cada individuo en el debate y el control por parte del moderador hubiera sido más complicado.

La duración de la discusión fue de 65 minutos en el primer caso y de 80 minutos en el segundo. La edad de los participantes osciló entre los 30 y los 70 años. Para que el grupo de discusión respetara la realidad, se acudió a los porcentajes de audiencia de la última corrida de toros y se trató de representar proporcionalmente las diferentes franjas de edad. El mismo procedimiento se siguió para determinar el sexo de los sujetos que participaron en el grupo de discusión.

Como mecanismo para realizar el extracto de la muestra para formar los grupos de discusión preparamos un cuestionario con una serie de preguntas que nos permitieron separar a las personas en dos grupos: por un lado, los sujetos a los que les gusta visionar contenidos taurinos y, por otro, los sujetos a los que no les gusta consumir este tipo de contenidos.

En este cuestionario, además de preguntar por los pertinentes datos personales para contactar con el individuo en el caso de que reuniera las condiciones que estábamos buscando, se pedía a los sujetos que valoraran de 0 a 10 una serie de contenidos televisivos: Concursos, Deportes, Informativos, Películas, Programas de actualidad, Programas de cocina, Programas del corazón, Programas de entretenimiento, Telenovelas, Toros y Series.

Para formar los dos grupos de discusión partimos de la valoración dada al punto número 10: toros. De esta manera, las personas que valoraban los contenidos taurinos con entre 0 y 4 puntos eran candidatos potenciales a formar parte de uno de los grupos de discusión, mientras que aquellos que valoraban los contenidos taurinos con 7 o más puntos eran personas que podían formar parte del otro grupo de discusión.

Tras la selección de los candidatos escogidos procedimos a citarles para la realización del grupo focal. Antes de comenzar la sesión dejamos claro que se trataba de una reunión en la que se podía hablar con total libertad. Además, les explicamos que todas las opiniones eran igualmente respetables y todas y cada una 
de las aportaciones que hicieran iban a servir para enriquecer la investigación, por lo que no debían tener ningún miedo a intervenir.

Tras una pregunta inicial introductoria teníamos preparadas una serie de imágenes de corridas de toros y programas taurinos. Estas sirvieron para que los participantes supieran el motivo por el que se les había reunido y, a su vez, sirvió para que cada uno de ellos manifestara su opinión sobre lo que acababa de ver.

Para organizar la sesión elaboramos previamente una pauta con los temas que queríamos abordar. Además, este guion nos permitía distribuir los tiempos de una manera más o menos equilibrada. En cualquier caso, al no saber cómo iban a reaccionar los participantes con cada pregunta hubo espacios que se alargaron más de lo previsto, otros resultaron más cortos de lo pensado y también la conversación derivó por unos temas, en relación con la materia, que no estaban preestablecidos. En cualquier caso, las diferentes respuestas se emplearon posteriormente para el análisis de la sesión. Por lo tanto, el guion que elaboramos se utilizó como una pauta flexible y abierta, que iba a depender del camino que tomara la discusión.

Pese a que la parte inicial del guion era similar para ambos grupos de discusión, la diferencia de criterio y de opinión que manifestaron ambos colectivos de personas en el cuestionario nos obligó a realizar una serie de preguntas específicas para cada uno de ellos. Así, vamos a empezar analizando las cuestiones que se prepararon en el guion para las personas que manifestaron su afición e interés por la emisión de contenidos taurinos:

1. Finalidades por las que ven programas taurinos.

2. Relación entre los toros y la cultura española.

3. Emisión de corridas de toros en la televisión pública.

4. Politización de la Tauromaquia.

5. Justificación de la necesidad de emisión de contenidos taurinos en la televisión.

6. Emisión de contenidos taurinos en horario infantil.

7. Situación en la que visionan programas taurinos.

8. Consumo de información taurina en otros soportes.

9. Relación entre la emisión de contenidos taurinos en la televisión y la mayor o menor calidad de la misma.

El primer bloque nos permitió responder a la siguiente pregunta: ¿por qué ven las personas programas taurinos? El siguiente punto nos facilitó encontrar una serie de justificaciones para establecer una relación entre los toros y la cultura española. Se explicó a los participantes que, según nuestra legislación, los toros son cultura, y se les pidió que justificaran esa decisión. Para estudiar la conveniencia o no de que la televisión pública española emita contenidos taurinos investigamos las razones por las cuales, según estas personas, la Tauromaquia debe formar parte de la programación de TVE. El cuarto apartado nos permitió analizar las opiniones de las personas aficionadas a los toros sobre la politización o no de la Fiesta Nacional. Esta cuestión se relaciona con las prohibiciones de las corridas de toros en algunas CC.AA y se deriva también a conversaciones sobre el nacionalismo. 
El quinto epígrafe se empleó para encontrar los razonamientos que las personas aficionadas a los toros esgrimirían para justificar la presencia de programas taurinos en televisión. Para profundizar sobre esta cuestión, se explicó a los participantes que TVE solamente emite un programa taurino semanal: Tendido Cero.

La relación sobre la posible "violencia animal", como así fue clasificada la Fiesta por el Manual de Estilo de RTVE, y los horarios de protección infantil fueron analizados a continuación. Esta cuestión nos permitió reflexionar sobre la conveniencia o no de que sea el Ente Público el que determine los contenidos que deben ver los niños en la televisión. Se analizó, también, la influencia de las figuras paterna y materna en la aproximación de los más pequeños hacia este tipo de contenidos.

También se les preguntó a los participantes por la forma en la que visionan este tipo de programación. Esta cuestión nos permitió conocer si la emisión de programas taurinos es proclive a un visionado familiar o es un producto que se consume de modo individual.

Debido a la escasa oferta taurina en la televisión pública, tanto estatal como autonómica, el octavo punto se utilizó para comprobar si esa oferta era suficiente o, si por el contrario, acostumbraban a buscar información taurina complementaria en otros soportes.

En el último punto nos centramos en la repercusión que tendría una mayor emisión de programación taurina en la calidad de la televisión actual.

Por otro lado, en el guion elaborado para el debate con personas que no visionan contenidos taurinos en televisión, las pautas fundamentales fueron las siguientes:

1. Pluralidad en la televisión actual.

2. Motivos por los que no visionan contenidos taurinos.

3. Emisión de corridas de toros en la televisión pública.

4. Relación entre los toros y la cultura española.

5. Influencia de la ideología política personal en el no visionado de programas taurinos.

6. Emisión de contenidos taurinos en horario infantil.

7. Prohibición de los contenidos taurinos en televisión.

La primera pregunta nos proporcionó la información necesaria para averiguar, sin haber presentado todavía el tema objeto de análisis, si los sujetos consideraban que la televisión emitía contenidos para todos los públicos. El siguiente bloque, una vez presentado el tema, nos facilitó conocer cuáles eran las motivaciones que llevaban a todos los individuos presentes en el grupo de discusión a evaluar con una nota inferior a 3 sobre 10 los contenidos taurinos. Para estudiar en profundidad las opiniones de los sujetos con respecto al tema de estudio preguntamos por la idoneidad o no de la emisión de corridas de toros en TVE.

El cuarto apartado nos permitió analizar las motivaciones de los sujetos de análisis para rechazar, en mayor o menor medida, la relación existente en nuestro país entre Tauromaquia y cultura. 
En la siguiente cuestión profundizamos sobre el posible condicionamiento ideológico de los sujetos estudiados a la hora de rechazar las emisiones taurinas. Esta cuestión nos permite investigar las verdaderas causas del rechazo a los toros, puesto que en este bloque se trataron aspectos desde el maltrato animal hasta la relación que tienen los toros con la simbología nacional.

Al igual que preguntamos en el grupo de discusión anterior, la sexta cuestión permite centrarnos en la necesidad de que exista un tramo horario de protección infantil para evitar que los menores de una edad determinada puedan visionar este tipo de contenidos.

Por último, nos centramos en abordar los motivos de la posible prohibición de los toros en nuestro país. Esta última pregunta es la más rica en matices, puesto que se trata de una cuestión interdisciplinar: economía, cultura, ecología, medioambiente, etcétera.

Durante el transcurso de ambos grupos focales, tomamos anotaciones sobre cómo se iban desarrollando los diálogos entre los diferentes sujetos para, posteriormente, analizar de manera pormenorizada todo lo que aconteció. Además, nos permitió anotar todas las referencias de comunicación no verbal que consideramos de interés para la investigación. Con todas estas apreciaciones, elaboramos un resumen al finalizar ambas jornadas que nos sirvió de guía para comenzar un análisis más exhaustivo de todos los razonamientos ofrecidos.

A continuación, transcribimos de manera textual la información más destacada que obtuvimos en ambos grupos focales. Después de organizar todo el material, releímos las transcripciones para anotar lo más significativo e importante y facilitar el análisis de los resultados.

\section{DISCUSIÓN}

\subsection{La Tauromaquia en la actualidad. Recorrido periodístico}

En la actualidad asistimos a una etapa en la que se cuestiona la existencia del periodismo taurino, especialmente en televisión. Se observa el crecimiento de la corriente antitaurina en nuestro país en los últimos años, espoleada por una creciente destaurinización de la sociedad. Se trata de un grupo social que se muestra totalmente en contra no solo de la emisión en televisión de este tipo de contenidos, sino de su propia existencia.

Pese a que existen organizaciones contrarias a la Tauromaquia desde hace décadas, se vive actualmente el momento de máxima tensión. La idoneidad o no de la existencia de la misma es protagonista en el debate social de nuestro país. El movimiento antitaurino experimentó un punto de inflexión en julio de 2010, cuando la Comunidad Autónoma de Cataluña prohibió la celebración de corridas de toros en su territorio.

Esta decisión provocó mucha polémica en la sociedad española. De hecho, organizaciones políticas y sociales pusieron en marcha una serie de medidas para 
devolver los toros a Cataluña y para blindarlos frente a posibles prohibiciones futuras. El Partido Popular entiende que la prohibición del Parlamento catalán supone una violación de la Constitución, por lo que recurrió ante el Tribunal Constitucional. El Tribunal todavía no ha emitido ninguna sentencia al respecto.

Además, desde la Federación de Entidades Taurinas de Cataluña se puso en marcha una recogida de firmas para promover una Iniciativa Legislativa Popular (ILP) que supusiera la declaración de los toros como Bien de Interés Cultural y, de este modo, lograr que en todo el territorio nacional se puedan celebrar corridas de toros. Esta ILP fue aprobada en febrero de 2013 en el Congreso de los Diputados.

Sin embargo, aunque la Tauromaquia sea declarada como Bien de Interés Cultural, no está muy claro desde un punto de vista jurídico-legislativo que las corridas de toros puedan volver a Cataluña, puesto que las competencias en esta materia corresponden a las Comunidades Autónomas y no al Estado español.

Por otro lado, si examinamos los antecedentes y nos centramos en los orígenes del periodismo taurino observamos la antigüedad del mismo. De hecho, la Tauromaquia ha estado presente en el periodismo español prácticamente desde la existencia de este:

La Tauromaquia está íntimamente unida a la Historia de España, al menos desde el S.XVI. Por esta razón, desde los orígenes de la información impresa en nuestro país, las fiestas de toros tienen en ella una presencia considerable. El paulatino desarrollo de la lidia coincide con la introducción y expansión de la imprenta en la Península y parece consolidarse de forma paralela a la incipiente actividad periodística en los siglos XVII y XVIII (De Haro de San Mateo, 2011, p. 44).

La presencia de contenidos taurinos en la prensa regular se irá afianzando hasta llegar a nuestros días. Además, en la pasada centuria surgieron una serie de revistas especializadas en la materia muy importantes, como El Ruedo, Tierras Taurinas, Cuadernos de Tauromaquia, Aplausos o 6TOROS6, algunas de las cuales ya han desaparecido.

En radio, por su parte, destacan los programas Clarín de Radio Nacional de España, El Albero de Cope, Carrusel Taurino de Canal Sur Radio o Los Toros de Cadena SER. Además, otras emisoras, como Onda Cero, han optado por emitir solamente online este tipo de contenidos.

Aunque, como ya hemos mencionado, los toros han tenido mucho peso en la historia de nuestra televisión, el papel que juega ahora mismo la Tauromaquia es, más bien, secundario:

La Tauromaquia es la cenicienta de la televisión en nuestros días. De entre las cadenas privadas, solo Canal Plus sigue ofreciendo a sus abonados una extraordinaria cobertura de las principales ferias, ya que el resto solo se acerca a la Fiesta muy puntualmente y ha dejado de retransmitir festejos. (...) En cambio, las cadenas autonómicas sí retransmiten un buen número de espectáculos taurinos cada temporada y ofrecen amplia y variada información 
del mundo de los toros a través de programas especializados. Al Quite de Canal Nou, Al Natural de 7 Región de Murcia o Tiempo de Toros de Castilla La Mancha Televisión son algunos de los espacios más destacados (De Haro de San Mateo, 2011, p. 47).

El hecho de que la Fiesta de los Toros sea, atendiendo a la legislación, patrimonio histórico y cultural de España y de otros países latinoamericanos ha provocado que tradicionalmente se haya originado un fenómeno de identificación grupal en torno a la misma. Además, el masivo seguimiento de las corridas de toros en un pasado no muy lejano de nuestro país ha permitido que la mayoría de los españoles haya sentido la Tauromaquia como algo propio, lo que ha provocado el surgimiento de un sentimiento de identificación grupal en torno a los toros.

Además, la importancia de la Tauromaquia en nuestro país ha provocado su estudio desde diferentes áreas del conocimiento, aunque las más destacadas investigaciones corresponden a tres disciplinas concretas: Filosofía, Historia y Sociología. En estas tres áreas se han producido el mayor número de trabajos sobre la Tauromaquia. Como ejemplos podemos citar Filosofía de la Tauromaquia (1842) de Santos López Pelegrín, Historia de la Tauromaquia (2000) de Bartolomé Bennassar o Pan y Toros (2009) de Eugenio Noel.

Las aportaciones periodísticas en la materia son numerosas desde la perspectiva de la prensa escrita, aunque algo más escasas si abordamos la cuestión desde lo audiovisual. De hecho, tras una exhaustiva búsqueda en la Red de Bibliotecas Universitarias de publicaciones de todas las disciplinas relacionadas con el tema objeto de análisis solo hemos encontrado un estudio que relacione la Tauromaquia con emisiones taurinas en televisión. Se trata de una tesis doctoral de la Universidad Complutense desarrollada por Miguel Ángel Moncholi Chaparro y dirigida por Francisco Esteve Ramírez. Fue publicada en el año 2004 con el título Las retransmisiones taurinas en televisión en la Comunidad Autónoma de Madrid: periodo 1992-1996.

Al margen del citado estudio, todas las aportaciones del periodismo audiovisual a la materia se centran en la presencia de este tipo de contenidos en los medios de comunicación, sin entrar a valorar los tipos de audiencia, su volumen o las motivaciones que llevan a esta a consumir este tipo de contenidos.

Pese al escaso bagaje investigador, el periodismo taurino cada vez está más implantado en las Universidades españolas y latinoamericanas. En muchas de estas, este tipo de periodismo tiene forma de asignatura optativa o está encuadrado dentro de Periodismo Cultural. En otras está presente en los cursos de verano. La Universidad Internacional Menéndez Pelayo de Santander, la Universidad Complutense de Madrid, la Universidad de Granada, la Universidad de Jerez, la Universidad de Málaga, la Universidad de Segovia, la Universidad de Sevilla o la Universidad de Almería son solo algunos ejemplos de Universidades españolas que fomentan el periodismo especializado en materia taurina:

Como se ha podido comprobar, el mundo de los toros está íntimamente ligado a la universidad y esta unión se ha intensificado en los últimos años a pesar de 
la creciente corriente anti-taurina que impera en el contexto actual. A pesar de ello, podemos concluir que el mundo de los toros ha entrado con fuerza en el ámbito universitario gracias a la iniciativa de numerosos docentes e investigadores que han querido resaltar la importancia cultural del mundo taurino (Rivera Flores, 2010, p. 143).

\subsection{Resultados de la investigación}

Una vez realizado en el epígrafe anterior este doble repaso a la Tauromaquia, desde una perspectiva comunicativa y desde otra social, entendemos que los resultados de la investigación, fruto de la realización de los ya explicados grupos focales, que aquí se presentan pueden contribuir a explicar los principales motivos y razones que llevan a este arte a ocupar el lugar que actualmente ocupa en nuestra sociedad. En estos resultados se indagan en los principales argumentos que las personas esgrimen para visionar y apoyar, o no hacerlo, este tipo de contenidos y vienen a confirmar o refutar todas apreciaciones hasta ahora presentadas.

\subsubsection{Finalidades por las que visionan o no programas taurinos}

La mayoría de las respuestas de los sujetos que ven de forma habitual programas taurinos es: "los veo porque es algo que me gusta, me entretiene y he vivido desde hace muchos años".

También, alguno de los participantes manifiesta ver programas taurinos porque le proporciona satisfacción cultural: "cuando ves una corrida de toros bien lidiada estás viendo una obra de arte, igual que cuando vas a un museo"; "el ambiente, el puro, todo lo que rodea... es algo que se te mete dentro".

La admiración hacia los toreros es otra de las principales razones esgrimidas: "estar delante del toro tiene mucho mérito. La preparación física que necesitan los toreros es impresionante. Yo veo al torero con el toro y veo una lucha igualitaria".

Otra de las justificaciones más recurrentes que argumentan los defensores de la emisión de contenidos taurinos es el respeto y la salvaguarda de una tradición nacional, motivo que suele mezclarse con intereses económicos: "a mí me gustan los toros porque son algo muy nuestro. Además, generan una cantidad de dinero tremenda".

Respecto a los sujetos que no consumen este tipo de programas las justificaciones que se emplean son bastante variadas. Varios individuos señalan la violencia ejercida sobre el animal como la principal de las motivaciones: "tanto sufrimiento me impacta. No aguanto ver como acribillan al animal"; "es una crueldad, no tolero ver eso en la televisión"; "¿qué clase de desalmado puede hacer daño a los animales por placer?".

También se alude a la falta de interés por la materia como uno de los principales motivos: "a mí no me gustan, por eso no los veo. Entiendo que puede ser algo intrínseco a nuestra cultura, pero no me gusta"; "lo de los toros no me va mucho, la verdad. Prefiero pasar mi tiempo viendo algo mejor o haciendo cualquier otra cosa". 
Además, se cuestiona que visionar este tipo de contenidos pueda tener alguna connotación positiva: "esa gente que dice que los toros son bonitos...lo será para ellos, para mí es una crueldad"; "no creo que sea muy agradable ver morir al toro de la Vega, por ejemplo", "entiendo que pudiera ser algo bonito en la Edad Media, pero, ¿Ahora?".

Por todo ello podemos deducir que, por un lado, los sujetos que visionan programas taurinos lo hacen porque les entretiene, les gusta y es, para ellos, una tradición que debemos respetar y proteger. Por otra parte, los individuos que no consumen este tipo de programas lo hacen o bien porque sienten un profundo rechazo hacia la Fiesta o bien porque no se sienten atraídos por la misma.

\subsubsection{Relación entre los toros y la cultura en España}

Entre los sujetos que visionan contenidos taurinos hay unanimidad en esta cuestión: "los toros son arte y cultura española"; "es arte pero también es sufrimiento, y eso es lo que hace de los toros algo especial, diferente", "es algo muy nuestro, forma parte de la cultura. A mí lo que me gustaría es que la televisión ayudara un poco. Mucha gente no podemos pagar el precio de las entradas y estaría bien que pudiéramos seguir esta parte de nuestra cultura a través de la televisión, como se ha hecho siempre".

Por otro lado, la respuesta entre las personas que no consumen contenidos taurinos es gradual: "acepto que se hable de cultura por la jerga que rodea a la Tauromaquia, por los vestidos, por la música...pero por el toro en sí, desde luego que no"; "los toros son cualquier cosa menos arte y cultura, por Dios. Y tampoco es una Fiesta Nacional, ¿cómo va a ser esa salvajada una Fiesta Nacional? Eso ni es arte ni es cultura, eso es tortura"; "si los toros son cultura, hay que borrarla"; "una cosa es que formen parte de nuestra cultura y otra que sean cultura, que, para mí, no lo es".

\subsubsection{La televisión y los toros}

En este punto también apreciamos cierta unanimidad entre los seguidores de los programas taurinos en televisión. La mayoría de ellos apuesta por que las televisiones públicas (TVE y, en Aragón, Aragón TV) emitan corridas de toros y programas que versen sobre Tauromaquia. Las razones que esgrimen son variadas: "los toros darían bastante audiencia, como así se vio con la corrida que emitió TVE el verano pasado"; "la televisión tiene que emitir corridas porque mucha gente no puede ir a la plaza a verlas. Es una manera de ayudar a difundir la Fiesta, sobre todo entre los más jóvenes"; "la retransmisión de corridas obedece a una cuestión de libertad y de justicia. En este país hay mucho taurino que está pagando las televisiones públicas con sus impuestos, ¿por qué no vamos a poder ver corridas entonces?"; "ahora mismo solo los ricos pueden ver los toros: o bien porque van a la plaza o bien porque se pueden abonar a Canal+. Si las emitiera TVE estarían al alcance de todos". En este punto, vuelve a producirse cierta división entre los no seguidores de contenidos taurinos. Como en el resto de cuestiones, las respuestas se gradúan, lo que nos permite distinguir algunas reflexiones basadas en la tolerancia y en la coexistencia entre taurinos y no taurinos, mientras que otros sujetos apuestan directamente por la eliminación de los toros en la televisión. Así, 
como ejemplo de la primera postura podemos citar las siguientes sentencias: "TVE tiene que apostar por contenidos para todos, nos gusten más o menos"; "¿desde cuándo hay que dejar de emitir contenidos que no nos gustan?"; "estamos en un país plural y libre, ¿por qué no van a emitirse?". Mientras que, como mencionamos anteriormente, encontramos otras respuestas más radicales: "no se deben emitir contenidos en los que la gente disfruta con la violencia, me da pena y asco"; "hay que evitar a toda costa que en la televisión emitan ese tipo de contenidos".

Pese a que la legislación española actual, como hemos explicado anteriormente, considera que la Tauromaquia es parte de la cultura de nuestro país y establece el deber de protegerla, si por algo se caracteriza la televisión pública actual es por la escasez de programación al respecto. Solo Tendido Cero se puede clasificar como programación taurina en el ente público. Surge entonces el debate sobre si este espacio es suficiente para garantizar la pluralidad en el ente público sobre este aspecto. De esta forma, los partidarios de la emisión de programas taurinos consideran que no, que TVE tendría que dedicar más tiempo en su programación a la Tauromaquia. Además, se señaló que una mayor pluralidad de contenidos haría ganar en calidad a la televisión pública.

Por otro lado, en el grupo focal compuesto por personas no partidarias de la Tauromaquia había división de opiniones. Así, mientras las personas de mayor edad afirmaban que la inclusión de más contenidos taurinos no tenía que suponer ningún problema, el sector más joven del mismo abogaba por la erradicación absoluta de la programación taurina en la televisión pública.

\subsubsection{Ideología en la Tauromaquia}

La sombra política está presente en la Tauromaquia española de las últimas décadas. El uso de multitud de simbología tradicionalmente ligada al sector más conservador de nuestro país (la bandera nacional, el paso por la capilla antes de saltar al ruedo, la presencia de las autoridades reales en determinadas corridas de toros, etcétera) hace que la Tauromaquia aparezca ligada a lo que se viene a llamar la derecha.

Sin embargo, ni los taurinos ni los no taurinos terminan de estar de acuerdo en esta cuestión. En este punto llama la atención que cuanto más joven es el participante que interviene, más politiza el tema. Así, por ejemplo, los participantes de menor edad del grupo a favor de los toros se manifiestan en los siguientes términos: "es evidente que el público que va a las plazas tiene un sesgo"; "yo siempre he creído que los toros son para gente de derechas, así lo he oído siempre". Sin embargo, dentro del mismo grupo focal, los participantes de mayor edad opinan de manera diferente: "los toros no pertenecen a nadie, son una Fiesta para todos"; "al contrario de lo que pensamos, los toros siempre han sido más de izquierdas, más del pueblo obrero, aunque ahora las cosas parece que han cambiado".

En el otro grupo se produce la misma división de pareceres. Vuelve a influir la variable edad en la postura de los sujetos. De este modo, los más jóvenes son los que establecen una mayor relación entre toros e ideología: "claro que sí que hay relación. Las personas que van a los toros son de derechas. Lo mismo sucede con 
las personas que rechazamos la Tauromaquia, también tenemos una etiqueta que, generalmente, se ajusta a la realidad". Al igual que en el grupo anterior, las personas de mayor edad rechazan este argumento: "No tiene nada que ver una cosa con la otra. Los toros te gustan o no te gustan, da igual de qué color seas"; "decir que los toros tienen relación con la ideología de las personas es decir que García Lorca era de derechas, ¿no?”.

En este aspecto, en ambos grupos de discusión el factor económico sale a relucir cuando se está hablando del factor ideológico. Por ello, parece que el elevado precio de las entradas solamente posibilita la asistencia de gente adinerada a las plazas, estableciéndose una clara relación entre gente pudiente económicamente y gente de ámbito conservador. Esta relación se establece indistintamente en ambos grupos focales y se manifiesta de la siguiente manera: "los toros son un espectáculo muy caro, y eso marca quien puede ir y quién no. ¿Acaso un obrero tiene dinero suficiente para pagar el precio que se pide?"; "el precio es prohibitivo. Es un dinero que solo pueden pagar las personas que tienen más nivel adquisitivo. $Y$ a esas personas se las asocia con una ideología, no sé si con más o menos fundamento".

Finalmente, también se apunta la posibilidad de que la Tauromaquia englobe tradiciones de uno y otro lado: "los toros de copa y puro, los toros de plaza grande son para gente rica y de derechas. Los toros como disfrute en la plaza del pueblo, con la música de fondo, son para gente obrera y de izquierdas".

\subsubsection{Toros en horario protegido}

Una de las cuestiones que más se debaten cuando se especula con el posible regreso de las corridas a TVE de manera regular es el respeto al horario de protección infantil u horario protegido. En España, las corridas de toros se suelen celebrar a las 17:00h, es decir, en pleno horario de protección infantil.

Por ello, la necesidad de modificar este horario o de aclimatar la emisión de las corridas de toros o de programas taurinos a un horario donde se respetara esta protección fue otro de los temas tratados en los debates. El grupo de los sujetos favorables a los toros expresó, por unanimidad, la necesidad de acabar con la calificación de franja horaria protegida por considerar que "no debe ser el Gobierno el que diga lo que los niños tienen que ver o no, para eso estamos los padres". Además, muchos de ellos manifestaron su indignación al conocer que el anterior Manual de Estilo de RTVE calificaba los toros como "violencia animal”. "¿Entonces nosotros somos violentos? Ya vale de tonterías, por Dios". También se señala a la política como la principal culpable de esta situación: "eso del horario protegido es una excusa de los políticos para quitar los toros de la televisión. Es un argumento endeble, sin sentido, cobarde". Además, se comparó la violencia taurina con la violencia que se percibe en otros programas, como en los deportivos: "si un niño ve la F-1 y ve un piloto estrellarse y morir... ¿eso no es violento? Pues nada, a quitar la F-1 del horario infantil. Es todo hipocresía".

En el otro grupo volvió influir la variable edad a la hora de determinar la respuesta hacia un sentido o hacia otro. Así, las personas de mayor edad señalaban, al igual que en el otro grupo, la responsabilidad paterna como principal origen del control 
infantil, por encima de cualquier horario. Sin embargo, los más jóvenes consideran que es "absolutamente necesario" que se controlen los contenidos que se emiten en las diferentes franjas horarias.

\subsubsection{Prohibición de los toros en la televisión}

Esta cuestión fue objeto de debate en el grupo de discusión de aquellos que se declaran no aficionados a los toros. En este punto, como en alguno de los anteriores, la variable edad vuelve a ser decisiva. Así, los participantes más jóvenes no planteaban abiertamente la prohibición, pero sí que señalaban que sería "adecuado que este tipo de 'festejos' se acabaran", aunque alegando que la mejor manera de que se acaben los toros es "que la gente deje de acudir". Sin embargo, las personas de más edad afirmaron con rotundidad que la solución no pasa por prohibir la Tauromaquia, sino que la mejor opción es dejar absoluta libertad en la materia.

\section{CONCLUSIONES}

Procedemos a resumir las conclusiones a las que llegamos tras realizar todo el proceso de investigación:

1. Los principales motivos por los que las personas deciden visionar programación taurina son los siguientes: les sirve como medio para entretenerse y divertirse. Además, disfrutan visionando este tipo de contenidos, es decir, encuentran una serie de gratificaciones. Tal y como apunta la Teoría de los Usos y las Gratificaciones, las necesidades principales de la audiencia, y en este caso en concreto de los seguidores de programas taurinos, son: identidad personal referencias a la niñez y una simbología común-, relaciones personales, diversión y escapismo.

2. Por otro lado, los motivos por los que las personas deciden no consumir este tipo de contenidos se sitúan de manera dispersa en una escala gradual. Así, la mayoría de estos sujetos rechazan el visionado porque no satisface ninguna necesidad de ocio ni de escapismo. También es destacable el rechazo a la violencia ejercida sobre el toro bravo como una de las principales motivaciones que lleva a estas personas a desechar la sintonización de este tipo de programación audiovisual.

3. Un aumento en la oferta de contenidos televisivos taurinos en las televisiones públicas estatales y autonómicas es necesario para garantizar el respeto al pluralismo y satisfacer la demanda de servicio público. El espacio que se dedica a la Tauromaquia en la televisión pública actual es escaso e insuficiente, aunque se reconoce el papel de protección de la Fiesta que realizan algunas televisiones autonómicas. Sin embargo, se considera que la emisión de corridas de toros es fundamental para que los televidentes taurinos puedan ver satisfechos sus derechos para con la televisión pública estatal y, a su vez, para que esta cumpla el deber constitucional de garantizar el respeto y el espacio tanto de los sectores mayoritarios como minoritarios de nuestro país.

4. El horario de protección infantil no debería ser ningún obstáculo para la emisión de contenidos taurinos en la televisión pública. Tanto las personas que visionan contenidos taurinos como las que no lo hacen consideran que la función principal de la televisión pública no debería ser poner límites a la libertad de los 
ciudadanos, aunque sea en beneficio de una supuesta protección de los menores, sino que esa responsabilidad es competencia exclusiva de los padres del menor, sin posibilidad ninguna de injerencia del poder público estatal.

5. Atendiendo a los datos de la última corrida de toros emitida por TVE, la audiencia de los contenidos taurinos se reparte de forma equilibrada entre hombres y mujeres, pero no así entre las diferentes franjas de edad, siendo el sector de personas mayores de 45 años el que representa cerca del $85 \%$ de la audiencia total de los contenidos taurinos.

6. La mayor parte de los sujetos que visionan programación taurina lo hacen acompañados por otros sujetos, especialmente por familiares. En la mayoría de las ocasiones este hecho se produce para intentar inculcar a los familiares más cercanos todos los conocimientos técnicos necesarios para comprender el toreo.

7. De hecho, la mayor parte de los taurinos recalcan la necesidad de que el visionado se realice de forma conjunta cuando haya menores implicados por la necesidad de justificar desde un punto de vista ético y moral, además de todas las vicisitudes técnicas mencionadas en el párrafo anterior, la Tauromaquia.

8. Las personas que consumen de forma habitual contenidos taurinos lo hacen a través de la televisión, sin emplear, en la mayoría de los casos, otros medios alternativos como la radio, la prensa o Internet. Este hecho responde, especialmente, a la edad de las personas que visionan este tipo de contenidos, que no suelen estar acostumbrados a descargarse contenidos en Internet.

9. Los individuos que visionan programación taurina consideran que la Tauromaquia es parte de la cultura española y, por ello, algo que el Estado español debería proteger y promocionar.

10.Sin embargo, entre los no taurinos esta cuestión es objeto de debate. Un sector de este grupo reconoce un mínimo componente cultural en este tipo de programación -moda, música, jerga especializada-, mientras que otro sector entiende que la Tauromaquia no casa con el concepto de cultura del Siglo XXI.

11. La edad es una variable que determina la toma de posiciones más o menos tolerantes con respecto a la Tauromaquia en el sector de los no taurinos. Así, las personas de menor edad se muestran más favorables a la prohibición de los festejos taurinos y, lógicamente, a su no difusión, mientras que las personas de edad más avanzada manifiestan una mayor tolerancia en este aspecto, ya que relativizan más la cuestión.

12. Se admite cierto grado de violencia en la emisión de festejos taurinos y de corridas de toros. Los seguidores de este tipo de programación entienden que este componente violento es mínimo y no superior al que se puede encontrar en otros programas televisivos que no están sometidos a ninguna restricción legal ni tampoco subyugados por un supuesto control ético y moral.

13. Por otro lado, las personas que no visionan programación taurina entienden que el componente de violencia es bastante elevado y evitable.

\section{REFERENCIAS}

Bennassar, B. (2000). Historia de la Tauromaquia: una sociedad del espectáculo. Valencia: Pre-textos. 
De Haro de San Mateo, M. V. (2011). El estudio del periodismo taurino: revisión y actualización bibliográfica, en Doxa comunicación, (13). Recuperado de www.doxacomunicacion.es/pdf/doxa132.pdf.

De Haro de San Mateo, M. V. (2011). Los toros en la prehistoria de TVE, en Asociación Española de Investigación de la Comunicación. Recuperado de www.ae- ic.org/tarragona2012/contents/comunicacions cd/ok/185.pdf.

Europa Press (2012). Consultado el 04 de Febrero del 2013. Recuperado de www.europapress.es/tv/noticia-regreso-toros-tve-fue-seguido-115-millonespersonas-20120906123011.html.

García-Matilla, A. (2010). Los informativos diarios en BBC y TVE. Madrid: Ediciones de La Torre.

Ley 10/1991 sobre potestades administrativas en materia de espectáculos taurinos, 82 B.O.E. § 8266 (1991).

Ley $17 / 2006$ de la radio y la televisión de titularidad estatal, 134 B.O.E. $§ 9958$ (2006).

Ley 7/2010 General de la Comunicación Audiovisual, 79 B.O.E. § 5292 (2010). López-Pelegrín, S. (1842). Filosofía de los Toros. Madrid: Boire Editor.

Marta-Lazo, C. (2009). El EEES y el proyecto final en los grados de comunicación. Madrid: Fragua.

Medina-Laverón, M. (2006). Calidad y contenidos audiovisuales. Pamplona: Eunsa. Moncholi-Chaparro, M.A. (2004). Las retransmisiones taurinas en televisión en la Comunidad Autónoma de Madrid: periodo 1992-1996. (Tesis inédita de doctorado). Universidad Complutense de Madrid, Madrid.

Noel, E. (2010). Pan y Toros. Madrid: Extramuros Edición.

Real Decreto 1151/2011, 09 B.O.E. § 14253 (2011).

Rivera-Flores, J. (2010). El periodismo taurino en las Universidades españolas e hispanoamericanas, Revista de la SEECI, (21). Recuperado de www.ucm.es/info/seeci/Numeros/Numero21/InicioN21.html.

RTVE. Consultado el 07 de Abril del 2013. Recuperado de http://codigodeautorregulacion.rtve.es/. 